\title{
Considerations for the Design of a Central Counterparty for the Mexican Money Market*
}

\section{Consideraciones para el diseño de una contrapartida central para el mercado de divisas mexicano}

\author{
Miguel de Lascurain M. ${ }^{1}$
}

Received: March 3, 2011

Accepted: August 4, 2011

\begin{abstract}
The financial crisis has brought the problems of regulatory failure and unbridled counterparty risk to the forefront in financial discussions. In the last decade, central counterparties have been created in order to face those insidious problems. In Mexico, both the stock and the derivatives markets have central counterparties, but the money market has not. This paper addresses the issue of creating a central counterparty for the Mexican money market. Recommendations that must be followed in the design and the management of risk of a central counterparty, given by international regulatory institutions, are presented in this study. Also, two different conceptual designs for a central counterparty, appropriate for the Mexican market, are proposed. Final conclusions support the creation of a new central counterparty for the Mexican money market.
\end{abstract}

Keywords: Central counterparty, money market, international regulatory institutions.

\section{Resumen}

La crisis financiera ha puesto en la agenda de las discusiones financieras los problemas sobre fallas en las regulaciones y el riesgo descontrolado de la contrapartida. En la última década, se han creado contrapartidas centrales para enfrentar estos insidiosos problemas. En México, tanto la bolsa como los mercados de derivados tienen contrapartidas centrales, pero el mercado de divisas no. En este estudio se presentan las recomendaciones que deberán seguirse para el diseño y manejo de riesgo de una contrapartida central, hechas por instituciones reguladoras internacionales. Al mismo tiempo, se proponen dos diseños conceptuales diferentes de contrapartidas centrales, apropiadas para el mercado mexicano. Las conclusiones finales sustentan la creación de una nueva contrapartida central para el mercado de valores mexicano.

Palabras claves: Contrapartida central, mercado de divisas, instituciones reguladoras internacionales.

* The author is grateful to Dr. Francisco Solís (Banxico), to Ing. Arturo Palacios (INDEVAL) and to Ing. Gilberto Iglesias (ITAM), for their valuable discussions, suggestions and recommendations. An acknowledgment is also extended to the Asociación Mexicana de Cultura, A.C. for its support.

1. Industrial and Operations Engineering Department, Instituto Tecnológico Autónomo de México. $<$ mdelasc@itam.mx>. 


\section{INTRODUCTION}

One distinguishing feature of the Mexican Financial System is the relatively large size of its money market. Every day, close to two trillion pesos ${ }^{1}$ is settled among market participants. A figure close to the Mexican GDP, considered to be around 10 trillion pesos, is thus traded in five operating days (El Financiero, 2008). By size, Mexico is the $14^{\text {th }}$ economy of the world; it is estimated that the Mexican money market is the $8^{\text {th }}$ largest, ranked by daily amount traded. A more striking comparison with the stock market is given on Table $1^{2}$.

The Mexican Central Securities Depository (SD INDEVAL) undertook a major reengineering change in a project that started in 2005 (Romero et al. 2008). The implementation of the project, named Dali System, won the prestigious Edelman Award in 2010 (Muñoz et al. 2011). Since the beginning of the project, it was interesting to find that the Mexican stock exchange (Bolsa Mexicana de Valores or BMV), uses a central counterparty (Contraparte Central del Mercado de Valores). However, the Mexican money market -being by far more important than the former - does not. At the time, several discussions were held about the matter, but the realization of a formal study was deferred.
The subprime crisis, followed by the fall of Bear Stearns, Lehman Brothers, American Insurance Group, and the disappearance of all five big American investment banks, have brought the topics of regulatory failure and counterparty risk to the forefront in financial discussions (The Economist, Aug 2008, Oct 2008, Nov 2008). One way to ameliorate that risk, providing the potential benefits of a central regulator, is to utilize a central counterparty, that is, a financial institution that acts as buyer to market participant sellers, and seller to market participant buyers. Thus, the interest in a central counterparty for the Mexican money market was revived.

The objective of this paper is to analyze what are the major factors that must be taken into account in the design of a central counterparty for the money market in Mexico. The purpose of the study is fully supported by authorities of the Mexican Central Bank (Banxico) and by the BMV, which is closely associated to the SD INDEVAL ${ }^{4}$. Some of the underlying concepts are general for any central counterparty, so the study may be of interest to other readers.

This paper is divided as follows: Section 2 offers a definition of a CCP, and its main advantages and

Table 1

Mexican Money and Stock Market Operations

\begin{tabular}{lcccc}
\hline & \multicolumn{2}{c}{ Money Market } & \multicolumn{2}{c}{ Stock Market } \\
\hline & $\begin{array}{c}\text { Average Daily } \\
\text { Amount Traded } \\
(\text { DVP) }\end{array}$ & $\begin{array}{c}\text { Average Daily } \\
\text { Number of Titles } \\
\text { Traded } \\
\text { (DVP) }\end{array}$ & $\begin{array}{c}\text { Average Daily } \\
\text { Amount Traded }\end{array}$ & $\begin{array}{c}\text { Average Daily } \\
\text { Number of Titles } \\
\text { Traded }\end{array}$ \\
\hline December 2008 & 1.84 trillion pesos & 134 billion & 3.82 billion pesos & 201 million \\
January 2009 & 1.72 trillion pesos & 132 billion & 4.13 billion pesos & 210 million \\
\hline
\end{tabular}

Source: Data provided by SD INDEVAL and the Mexican Stock Market.

1 The exchange rate is 1 US $\$=12$ pesos.

2 Although there is a very modern Mexican Derivatives Market, with Asigna acting as central counterparty, it was considered that stock trading has more similarities with bond trading than derivative contracts trading.

3 Delivery versus payment operations only.

4 BMV owns the right to collect $41 / 42$ of all future INDEVAL dividends, and has options to buy 41 of the 42 INDEVAL shares, if a modification in legislation ever allows this to happen. 
disadvantages are provided. Then, the most relevant recommendations for the design of a CCP, given by the International Organization of Securities Commissions (CPSS/IOSCO), are summarized. Following these, risk management procedures, provided by the same organization, are presented. An overview of the relevant characteristics of the Mexican money market and a brief analysis of two possible conceptual designs for a central counterparty are presented. Finally, the conclusions of the paper and recommendations for further work are given.

\section{CENTRAL COUNTERPARTIES}

\section{Definition}

Since the 1990s, central counterparties (CCPs) have become more and more commonplace as a cornerstone of financial market infrastructures. Before starting with any possible analysis of the design of a CCP, it is necessary to define what a CCP is, what are its functions, the risks which it faces, and its advantages and disadvantages. The most important CCPs worldwide are listed at the end of this section.

The European Central Bank defines a CCP as an entity that mediate itself between the counterparties to every trade, acting as the buyer to every seller and the seller to every buyer (ECB 2004, 2007). This implies that the CCP is the counterparty for every seller and buyer; in other words, it acts as an intermediary.

The consequences of this mechanism are important because a well designed CCP can reduce the amount of counterparty risk that market participants face. This reduction of risk is a result of the concentration of knowledge that the CCP accomplishes during the process of managing all the transactions done in the market. The CCP knows who is buying and who is selling, but a given market participant may have a reduced knowledge about the others. Hence, the CCP may reduce the danger of speculation and, therefore, market distortions are lessened.
Then, the mere presence of a party that is aware of all participants can help to reduce dramatically the risks for all of them, while helping to maintain the market operating in normal conditions. That is why trades on many major stock exchanges (including London and Tokyo) go through a central counterparty. As a result of their great contribution to the functioning of the stock markets, CCPs have been introduced recently to other markets, such as over-the-counter (OTC), derivatives and securities repurchase markets.

\section{Advantages and disadvantages of a CCP}

In his thesis, Marco Rast (2007) enumerates the main advantages and disadvantages of the existence of CCP in a given market. Some of the most significant advantages are:

1. Simplified risk management / risk reduction: The settlement guarantees given by the Central Counterparty result in lower risks and lower equity costs.

2. Post-trade anonymity: In settlement processes thorough the CCP no information about the trading parties is disclosed.

3. Lower capital claims: If the Central Counterparty allows for the cross-border settlement of different markets, and a reduction in the number of existing clearing links, then this may result in the consolidation of the capital required for margins.

4. Netting: Increases the effectiveness, capacity and liquidity of the marketplace and reduces the amount of capital required by the participants for their trading activities.

5. Network simplicity (not mentioned by Rast): If there are $\mathrm{n}$ participants in the market and no $\mathrm{CCP}$, there might be $(\mathrm{n}-1) * \mathrm{n} / 2$ links among them. The existence of a CCP reduces the possible number of links to just $n$, thus simplifying the network for $n>3$. 
The main disadvantages of the presence of a CCP in a market are:

1. The advantages obtained from the presence of a $\mathrm{CCP}$ in the market are not equal for all the participants. The advantages acquired are directly correlated with the size of the participant.

2. In small markets where there are no CCPs, the total costs and the risk involved in setting up a CCP service are relatively high and may even have a counterproductive effect, so it is more advisable to join an existing CCP.

3. The most important disadvantage is the concentration of almost all the risks in a single party. If this party breaks down, then the functioning of the entire financial market is threatened.

4. A CCP can only implement its risk management instruments efficiently given sufficient trading liquidity.

Clearly, the above mentioned advantages apply to any market. The disadvantages may depend on the given market. In the case of Mexico, the second and the fourth disadvantages are not relevant. Regarding the first disadvantage, the same situation appears in central securities depositories and may be reduced by granting the same weight to every participant's share of the depository and by the active participation of the authorities.

\section{CCPs Organizations}

There are associations that group CCPs all over the world so they can exchange experience and information about potential problems that may occur. The biggest and most significant of these organizations is the CCP12, founded in 2001 by the 12 largest CCPs at that moment in Europe, Asia and America.

The purpose of the CCP12, according to its mandate, is to promote the industry's dialogue on the adoption of best clearing and risk management practices, regula- tory harmonization and pursuit of strategies which, in turn, will support the increase in cross border trading and facilitate interconnections between global markets, instruments and liquidity pools (2008). CCP12 deals with the growth of the volume of the operations, the emergence of liquidity pools, trading in new financial instruments, the movement from cash markets to more hybrid type OTC derivate instruments, and the concerns of regulators for greater transparency and risk management safeguards.

The 23 member organizations of CCP12 include:

- Australian Securities Exchange Ltd.

- The Brazilian Clearing and Depository Corporation

- Brazilian Mercantile \& Futures Exchange

- The Canadian Depository for Securities Ltd.

- Canadian Derivatives Clearing Corporation

- Cassa di Compensazione e Garanzia S.p.A.

- The Clearing Corporation of India

- Chicago Mercantile Exchange

- The Clearing Corporation

- The Depository Trust \& Clearing Corporation

- Eurex Clearing AG

- Hong Kong Exchanges and Clearing Ltd.

- Japan Securities Clearing Corporation

- LCH Clearnet Group Limited

- Korea Exchange

- National Securities Clearing Corporation Limited

- NASDAQ OMX

- The Options Clearing Corporation

- The Polish National Depository for Securities

- Singapore Exchange Limited / The Central Depository (Pte) Limited

- SD INDEVAL

- Taiwan Stock Exchange Corporation

- Tokyo Stock Exchange Group, Inc

\section{GENERAL CONSIDERATIONS FOR THE DESIGN OF A CCP}

The International Organization of Securities Commissions (CPPS/IOSCO, 2004) has published the following 
recommendations that must be taken into account in the design of a CCP.

\section{Legal Risk}

The legal system (including bankruptcy laws) should clearly support novation or open offer ${ }^{5}$, netting, default procedures, collateral and clearing fund arrangements, enforceability of a CCP's rules with regard to its participants, insolvency of the CCP, conflict of laws determinations, and a CCP's access to information about participants. If the legal framework is underdeveloped, opaque or inconsistent, the resulting legal risk will undermine a CCP's ability to operate effectively.

The legal framework must specify the moment in which the CCP acquires the responsibility with the participants and the moment in which those responsibilities end. The involvement of the CCP in the collateral must be clearly outlined and this collateral must be quickly accessible for the CCP so it can promptly meet its obligations.

The laws of the relevant jurisdictions should support the provisions of the CCP's legal agreements with its settlement banks relating to finality. Similarly, there should be a clear and effective legal basis for the finality of the transfers of financial instruments.

\section{Participation Criteria}

A CCP must stipulate the participants to have enough resources and a solid operational capacity to meet their obligations arising from participations in the CCP. Requirements should be clearly stated and publicly disclosed so as to promote certainty and transparency. To avoid discrimination against certain types of users, the criteria must be limited to deny the access only for

5 Novation implies that the original contract between the buyer and seller is extinguished and replaced by two new contracts, one between the CCP and the buyer and the other between the CCP and the seller. An open offer system implies that a CCP is automatically and immediately interposed in a transaction at the moment the buyer and seller agree on the terms. risk control reasons. In fact, the criteria should ensure participants are solvent, well managed and have good operational capacity. They should be able to process the expected volumes within the stipulated time.

\section{Measurement and management of credit exposures}

A CCP should limit its exposure to potential losses due to a participant default in normal market conditions through the request of guarantees or other control mechanisms. At the same time, a CCP can estimate its current credit exposure to every participant by marking each participant's more outstanding contracts to current market prices and netting any gains against any losses (Mark-to-market). A CCP should estimate this credit exposure frequently - at least once a day -, so that the estimate is reasonably accurate.

The most common mechanism that a CCP can use to protect itself against losses arising from a participant default is to request all of them to deposit a margin that is proportional to their potential losses.

\section{Margin Requirements}

The margin requirements must be enough to cover losses in case a participant's default occurs in normal market conditions. The need for these margin requirements is more evident for contracts that have a long duration, because the potential risk is directly correlated to the time of exposure.

When setting the margin requirements, the $\mathrm{CCP}$ should use models and parameters that capture the risks characteristics of the compensated products. Margin requirements impose opportunity costs on CCP participants, so the CCP needs to strike a balance between greater protection for itself and higher opportunity costs for its participants. Although these margin requirements are not intended to cover all possible losses, it is necessary that the CCP has the ability to make intraday margins calls to avoid building up risks. 


\section{Financial Resources}

A CCP must have enough financial resources to face, at least, a default of the participant to which it has the largest exposure in extreme but plausible market conditions. Although a CCP does not need to have resources to cover a default from all participants, it must consider the possibility that two or more participants may not fulfill their responsibilities at the same time.

To evaluate the adequacy of their financial resources, the CCPs must use stress tests in which they should assume extreme conditions in the market. In case that the tests indicate that resources are not enough, the CCP must inform the procedures that it will follow.

In the analysis of the adequacy of its resources, the CCP should only include those resources that are quickly available given a default. A CCP must obtain credit lines for the amount of resources that are not easily accessible in case of a default and wishes to use to meet this criterion. In some cases, the CCP asks their participants to pledge additional resources when a large default happens.

\section{Default Procedures}

These procedures are intended to secure the continuity of all the functions of a CCP by limiting the effect that a default could cause to the other participants. The objectives of the procedures are:

- To minimize the losses that a default may cause to the CCP and other participants.

- To enable the CCP to keep fulfilling its obligations.

Before a CCP can establish the default procedures, it must first define what a default is, how an event can be declared as default, if it is going to be declared default automatically or if someone is responsible of that (in which case should appoint who has that responsibility).
After that is completed, the CCP must issue a set of procedures about the measures that it will take when a default is declared. These procedures should allow the CCP the following:

- To define the modifications to be applied to the accounts of the participants in case of a default. A CCP should have arrangements or mechanisms to facilitate the transfer, closeout or hedging of a defaulting participant's proprietary positions promptly.

- To use any financial resource to cover losses or to fight back liquidity pressures.

It is necessary that the national legislation should back up the default procedures defined, so the CCP has no problem in applying them. Finally, these procedures must be made public to inform everybody and be able to adjust to them when necessary.

\section{Custody and Investment Risks}

A CCP should hold assets in a manner that the risk of loss or delay in its access is minimized, while the assets invested by a CCP should be held in instruments with minimal credit, market and liquidity risks. A CCP has the responsibility to ensure that such investments do not compromise its ability to use the funds for their intended purpose.

In the case where a CCP needs a custodian -a central securities depository (CSD) or a financial institution-, the CCP should determine if the custodial procedures and internal controls of its custodian are good enough to protect the securities against the custodian's insolvency, negligence, misuse of assets, fraud, poor administration, or inadequate record keeping. Of course, the custodian must have a solid financial position so potential losses could be covered easily.

\section{Operational Risk}

The importance of the operational risk lies in its capacity to impede the effectiveness of measures adopted to 
address other risks and to cause participants to incur in unforeseen losses. To minimize operational risk, CCPs should actively identify and analyze sources of risk, whether arising from the arrangements of the CCP itself, from those of its participants, or from external factors, and establish clear policies and procedures to address those risks.

All key systems, especially the technological ones, should be secure, reliable, and scalable (to be applied to different scenarios without the necessity of making great changes on them) and should have the capacity to deal with stressful circumstances. A CCP must have a contingency plan to face events that may cause its systems to fail. This contingency plans must include objectives, policies and procedures.

\section{Money Settlements}

ACCP should apply mechanisms that eliminate or reduce the credit and liquidity risks due to the use of banks to complete money settlements with its participants. To make such money settlements, a CCP should make arrangements with its participants and one or more banks (its own settlement banks). There can be identified two types of monetary settlements:

1. In the first type, the Central Bank is used as the settlement agent. Through the central bank model, a CCP's settlement bank risks are eliminated. However, this central bank model may not always be practicable because it requires a CCP to have access to an account with the central bank.

2. The second type is called the "settlement bank model". In this model, a CCP selects one or more banks that are going to be the ones that settle its transactions. Settlement banks should be subject to effective banking supervision and regulation; they should be well capitalized and have access to ample liquidity in the marketplace. At the same time, the banks should have the technical capacity to provide reliable payment services at the times and on the terms required by the CCP.

\section{Physical Deliveries}

Some of the settlements cleared by CCPs require (or permit) physical settlement. Those settlements imply a delivery by the seller to the buyer of the deliverable assets against cash payment. This physical delivery makes the CCP face all types of risks, especially principal risk.

If a CCP guarantees the delivery of a physical instrument, then the CCP faces a liquidity risk associated to the acquisition of such instrument, due to the possibility that the seller does not fulfill his responsibilities. Also, if a CCP has an obligation to make a delivery, the CCP should eliminate principal risk through the use of the available delivery versus payment (DVP) mechanism. A DVP mechanism links a system for transferring funds (payment) to a system for transferring the physical instrument (delivery) in a way that ensures that payment occurs if and only if delivery occurs.

When there is no DVP mechanism for settlements, a CCP should take other measures to mitigate principal risk like holding a margin to mitigate the pre-settlement price risk of a position. These margin deposits should be held until delivery is complete. Generally, the value of that margin might be less than the principal value at risk at delivery, so a CCP should build additional protections into the delivery process. Some CCPs require participants to pre-fund payments associated with deliveries or to provide some form of payment through an agent bank.

\section{Risks in Links between CCPS}

Links between CCPs bring great advantages to the participants. For instance, it allows the participants of a CCP for one market to trade in another market while clearing that trade through their existing arrangements. Links can deepen the liquidity in markets and they also help to reduce the costs of systems development and operation faced by CCPs because it enables them to share these expenses. These links between CCPs may take some of the following forms: 
1. One CCP becomes a clearing participant of another CCP without any further integration of systems.

2. The CCPs merge their systems to offer a single clearing platform.

Conversely, links could bring to the scene some risks, such as legal or operational risks. Legal risks are originated because of the differences between the laws and norms in places where the jurisdiction change; operational risks are originated due to the differences in the performance of the institutions that interact.

\section{Efficiency}

Some of the characteristics that a CCP must have to be efficient are the following:

1. CCPs should seek to meet the service requirements of participants in a cost-effective manner. This includes meeting the needs of its participants, operating reliably and having adequate system capacity to handle both current and potential activity.

2. When looking at the overall costs of CCPs, it is important to include both the direct costs of operating any facilities and indirect costs.

3. CCPs may use some mechanisms to improve efficiency like developing technical capabilities to meet operational service requirements of participants.

4. A CCP must establish communication procedures and standards that support straight through processing of transactions.

5. A CCP must periodically review its service levels, costs, pricing and operational reliability.

\section{Governance}

An effectively governed institution should meet a minimum of requirements such as the following ones:
1. Governance arrangements should be clearly specified and publicly available.

2. The board should contain suitable expertise and take into account all relevant interests.

3. The board should be accountable to owners and participants for their performance.

4. Reporting lines between management and the board should be clear and direct.

5. The board should be responsible for selecting, evaluating and, if necessary, removing the senior managers.

\section{Transparency}

It should be considered necessary that a CCP discloses its rules and regulations to the participants, their rights and obligations, the risks and the corresponding steps to mitigate them, costs of using their services, laws and general procedures. At the same time, the CCP should disclose appropriate quantitative information on its clearing, netting and settlement activities and risk management performance. The CCP should also inform clearly in what circumstances it will assume counterparty exposure and, of course, any restriction or limitations in the fulfillment of its obligations.

\section{RISK MANAGEMENT BY A CCP}

Any market presents some implicit risks in its daily operation due to the nondeterministic nature of the activities performed. If those risks are thoroughly analyzed, then there is a better chance to manage them so that the impact they cause on the functioning of the system may be minimized.

It is necessary to notice that the risks that a given $\mathrm{CCP}$ deals with may vary significantly if compared to the risks that others CCPs face. The particular risks that a CCP encounter depend really on the stipulations of its contracts with its participants. 
The Technical Committee of the International Organization of Securities Commissions (CPSS/IOSCO, 2004) identifies a set of common risks that the CCPs have to face and, in consequence, must manage. In the following, a list of the most common risks and the manner the CCPs actually manage them are synthesized.

\section{Counterparty Credit Risk}

\section{a. Definition}

This is the risk of a loss due to a participant's default, generally as a consequence of its insolvency. This risk can be divided into two categories:

1. Pre-Settlement risk: it is also known as "Replacement risk", and it refers to the loss from replacing open contracts with the defaulting participant.

2. Principal Risk: this deals with the loss in deliveries or payments from the defaulting participant.

If a participant commits a default, then the CCP would terminate its entire contracts; however, the CCP would keep meeting its obligations with the other participants. The chance that someone commits a default implies that a risk to the CCP arises. The replacement cost arises because the $\mathrm{CCP}$ has to liquidate the contracts at prices that may be different from the original ones. Finally, settlement risk arises when the full principal value is at risk. That happens when the settlement implies a delivery, but it is not a delivery versus payment model.

\section{b. Approach to Manage the Risk}

Most CCPs impose the participants some requirements so the risks associated with their activities could be minimized. These requirements are as follows:

1. Participation requirements. The CCP imposes the participants to meet minimum capital requirements and a certain operational capability to be admitted or to continue participating. The capital requirements are directly correlated to the level of risk that the activities of that participant imply.

2. Position or trading limits. CCPs may control the level of exposure they can face in relation with every participant so it can limit the potential effects that a possible default may cause.

3. Margin requirements. This requirement refers to the imposition that a CCP applies to the participants so that they provide collaterals (or guarantees) to cover potential future losses. Although these margins are supposed to cover a high percentage of the potential losses, they are not intended to cover the total amount.

4. Financial resources. A CCP must ask for the participants to have a sufficient amount of financial resources to back up their daily operations. Those financial resources can take the form either of assets held directly by a CCP or of contingent claims.

5. Default procedures. A CCP must have procedures in case some participant does not meet its obligations. Those procedures must specify the ability the CCP has to transfer, close-out or hedge positions of a defaulting participant quickly.

\section{Liquidity Risk}

When two participants make a deal agreeable to the CCP, it is immediately obligated to make and receive all payments agreed initially. In the daily operation there may be a moment when the transactions are not liquidated, and where the buyer has not paid the agreed assets to the CCP, but the CCP still has to meet its obligations to the seller. Therefore, the CCP has to use its own capital in order to pay the seller.

\section{Settlement Bank Risk}

This risk refers to the possibility that the bank that provides the cash for money settlements fails in meeting 
its obligations. This risk is eliminated by some CCPs by using the central bank as the liquidating bank.

\section{Custody Risk}

To manage credit risk a CCP could ask the participants to post a margin so the CCP can protect itself from the risk that arises as a result of the exposure it is facing. Having those margins implies a custody risk to the CCP. In this case, the CCP hires a third party to be the custodian. In turn, the custody risk would be the risk that the custodian may not meet its obligations.

In order to manage this risk, the CCP must verify that the custodian achieves the best safekeeping standards. The custodian's assets must be free of the claims of its creditors. Evidently, it follows that the custodian should demonstrate a solid financial position with robust internal controls.

\section{Investment Risk}

The CCP may have to invest its capital (equities and reserves) so that it can generate revenues and may cover some of the costs of operations. Those investments should be made in short-term bank deposits or securities that have minimal market risk. Although the investments could be almost risk-less, those investments face an implicit risk. That risk is the investment risk.

Thus, the CCP should limit its investment to liquid instruments and establish standards for the creditworthiness of obligors. Investments may also be secured. Limits on concentrations of investments by obligor may be utilized.

\section{Operational Risk}

This risk consists in the chance of having unexpected losses due to deficiencies in internal systems, human error, external events or management failure. To ensure that this type of risk is minimized, three types of measures should be taken:

1. Human personal should be trained and supervised adequately by personnel with expertise.
2. Internal procedures and systems should be reviewed frequently.

3. CCP's computer systems, communications systems, power systems and data feeds must be installed properly and they should count with redundancy systems so that the proper functioning is assured.

\section{Legal Risk}

This risk implies that the legal framework (laws and regulations) does not support the rules, the terms of contracts, the property rights or any other aspects of interest of a CCP. The CCPs must create a legal framework that supports entirely every aspect of its operations, including laws and rules to be applied to the participants.

\section{RELEVANT FEATURES OF THE MEXICAN MONEY MARKET}

A detailed description of the operation of the Mexican markets can be found in Romero et al. (2008). In this section, some relevant aspects of the operation of the money market are presented.

The main regulator of the Mexican money market is the Central Bank of Mexico (Banxico) through regulations on securities operations and on repurchase agreements ${ }^{6}$. Other authorities involved are the Comisión Nacional Bancaria y de Valores (CNBV, the Mexican banking and securities commission), and the Comisión Nacional del Sistema de Ahorro para el Retiro (CONSAR, the institution in charge of regulating the operation of pension funds in Mexico that receive federally mandated contributions from employers).

The main participants in the Mexican money market are:

- Banxico

- Credit institutions, local and foreign

6 Circular Única de Reportes. 
- Brokerage houses

- Pension funds

- Investment funds

- Insurance companies

- Institutional investors

Most money market operations are settled at INDEVAL.

The most important issuer of money market securities is the Federal Government. Banxico acts as the issueragent and depositary of those securities and holds weekly auctions of Government debt instruments. Mexican credit institutions and public and private companies are other issuers in the market.

Large numbers of securities are kept by pension funds and by other participants, like investment funds, insurance companies and institutional investors. The "rotation" of those securities is relatively low. It is relevant to mention that an important part of the securities are owned by foreigners, through the use of custodian banks.

By means of money market trade mechanisms, two participants agree on the terms of a deal. The participants may act for themselves or representing third parties, thus acting as custodians. Most trades are negotiated bilaterally over the phone, but there are other Electronic Trade Mechanisms (ETM) that should be taken into account like SIF, Remate, and Enlace, which are privately owned ${ }^{7}$. Central Bank's regulations specify that the terms and conditions of the deal must be transmitted electronically to INDEVAL's Dali System the day of the trade, to be matched, cleared and settled according to the terms and conditions negotiated by the participants.

Approved settlements must imply either of the following: Delivery versus Payment operations; Delivery versus Delivery operations (i.e., bond interchanges); Delivery Free of Payment operations (i.e., transferring bonds from one account to another); Payment operations

7 Today, they generate only approximately $6 \%$ of the trades. (i.e., interest payments); or a Payment versus Payment operation (i.e., currency operations) (Bank for International Settlements, 2003).

The most common way to obtain liquidity in the market is through the use of repurchase agreements, by which a participant sells its titles to other participant, with the promise to repurchase those titles in the future. By far, most repurchase agreements deal with Government titles, and over $95 \%$ of them are sameday transactions ${ }^{8}$. It is estimated ${ }^{9}$ that over $50 \%$ of the operations in the Mexican money market are same-day DVP operations linked to repurchase agreements.

In today's operation at INDEVAL, around 50 operations - of which around 13 are DVP - are cancelled at the end of the day due to lack of compliance by one of the participants. The participants involved are informed of the facts and they must settle their differences. Although this is a small percentage of the total of daily operations (in the order of 30,000), this fact shows the existence of risky operations that could be reduced by the presence of a CCP, or by some other mechanisms ${ }^{10}$.

To conclude, in the Mexican money market there is no global electronic exchange, since most transactions are carried through by telephone. This means that the operations are highly concentrated among few participants. It also means that the market is far from being free-of-risk.

\section{CONCEPTUAL OVERALL DESIGNS}

As has been discussed throughout the paper, the Mexican money market would be enhanced by the presence of a central counterparty. Two conceptual overall designs for a CCP for the Mexican money market may be presented as follows:

\footnotetext{
8 Banxico.

9 By INDEVAL.

10 It is worth mentioning that repurchase agreements are heavily regulated in the Mexican market. Also, INDEVAL offers to its clients a service called SAVAR, which manages collaterals for repurchase agreements.
} 
1. The Dali System has a single entry point. An entity that acts as a pure CCP placed at the entrance of the System may be developed and put into operation. It would only accept trades from the counterparties that comply with CCP rules and requirements, acting then as the buyer to every seller and the seller to every buyer.

2. An entity that acts with the dual purpose of an Electronic Trade Mechanism and CCP (ETM$\mathrm{CCP}$ ) may be designed and put into operation. Besides widening and deepening the operation of today's market, it would have the advantage that it would accept bids and offers in electronic market rounds of only pre-approved participants, thus preventing the emergence of risk, and strengthening anonymity.

The first design has the advantage of its simplicity and could include the current stock market operation done by the Contraparte Central del Mercado de Valores. The second one is more ambitious, because it implies the development of an electronic money market managed by a central counterparty. More on these topics is presented in the following section.

\section{CONCLUSIONS AND FURTHER WORK}

1. The Mexican Finance System has evolved in the past few years and it is now one of the most modern and efficient systems of the world. The recognition given by the Edelman Award gives credit to this advance.

2. A sample of cooperative behavior among the public, private and the academic sectors is the development of the Dali System, where a rules-based system, using a unique settlement algorithm, performs real-time clearing, netting and settlement of the transactions of Mexican securities markets. Developing a CCP for the money market could be another instance of such successful behavior.

3. Both the stock and the derivatives markets in Mexico use central counterparties, thus ameliorating the risk involved in their operations. A central counterparty for the money market is a natural extension and would offer overall risk reduction in the financial system.

4. It may be argued that the benefits obtained from the presence of a CCP in the market are not equal for all the participants. The benefits acquired are directly correlated with the size of the participant. The same situation appears in central securities depositories and it can be reduced by granting the same weight to every participant's share of the depository and by the active participation of the authorities.

5. The most important disadvantage of a CCP is the concentration of almost all the risks in a single party. If this party breaks down, then the functioning of the entire market is threatened. This argument must be used very carefully because it would disqualify the operation of modern central banks and central depositories, which have in-built mechanisms that prevent their failure. However, the same logic may be used in this case: the advantages of a CCP outweigh this disadvantage.

6. Nevertheless, risk concentration is an important issue. Thus, it is not advised to fuse the central counterparties that operate in the Mexican markets, since today most liquidity is provided to the whole financial system by Banxico, as discussed in section Risks in Links between CCPS.

7. Two different overall conceptual designs are offered in this work. The author strongly recommends the integrated ETM-CCP option, because it would reinforce today's operation of the Mexican money market, while providing it with strong risk-reducing mechanisms.

8. Further analyses in the following areas are required:

a. A statistical analysis of the transactions and operations carried by the market participants would give a better insight on how the market functions, and would discover the potential risk problems that have to be dealt-with in the design. 
b. A legal study must be launched to assess if the actual Mexican legal framework may support the operation of a CCP for the money market. Law changes, if needed, must be precisely identified and politically gauged. c. Cost-benefit analyses of both proposed designs have to be carried through.

\section{References}

Bank for International Settlements. 2003. Glossary of terms used in payments and settlement systems. Basel, Switzerland: Committee on Payment and Settlement Systems Publications.

CPSS/IOSCO. (2004, November). CPSS Publications, No 64.

Damoclean Days. (2008, August $\left.7^{\text {th }}\right)$. The Economist.

El Financiero, December 4 $4^{\text {th }}, 2008$.

European Central Bank. (2004). Annual Report, Glossary. $<$ http://www.ecb.int/home/glossary/html/index. en.html>.

European Central Bank - Federal Reserve Bank of Chicago (July 2007). The Role of Central Counterparties. Frankurt am Main, Germany: ECB.

Global 'CCP' Conference on Clearing, April 2008. <http:// www.jscc.co.jp/en/ccp12/materials/index.html>.
Muñoz, D. F., de Lascurain, M., Romero-Hernandez, O., Solis, F., de los Santos, L., Palacio-Brun, F. J., et al. (2011). INDEVAL Develops a New Operating and Settlement System using Operations Research. Interfaces, 41(1), 8-17.

Rast, M. R. 2007. The Central Counterparty, A settlement system trend? Swiss Finance Institute. $<$ http://www. ccp.sisclear.com/ccp/broschure-diploma-thesis. pdf $>$.

Romero-Hernandez, O., de Lascurain, M., Muñoz, D., Romero, S., Muñoz, D. G., Palacios, A., et al. (2008). Business Process Modeling for a Central Securities Depository. Business Process Management Journal, 14(3), 419-431.

Taming the Beast. (2008, October $\left.9^{\text {th }}\right)$. The Economist.

The Great Untangling. (2008, November $\left.6^{\text {th }}\right)$. The Economist. 